\title{
Electrical Breakdown of Small Gaps in Vacuum
}

\author{
N. Zouache and A. Lefort
}

\begin{abstract}
The comparison of the characteristics of an electric arc breakdown in vacuum between two silver or silver-nickel alloy convex electrodes, enabled us to show experimentally that the process initiating discharge in vacuum is the electronic emission at the micrometer scale. Increased content of nickel in the alloy improves the insulation and achieves high resistance to erosion for low power arcs. Heating in vacuum demonstrates the multiple layer structure of studied alloys. Secondary electron microscopy and energy dispersing spectroscopy of the electrode surfaces after breakdown, as well as the measurements of fall and delay times, enabled us to evidence the origin of the electric arc.
\end{abstract}

\section{INTRODUCTION}

$\prod^{\mathrm{N}}$ $\mathrm{N}$ addition to its fundamental scientific aspects, the study of electrical conduction mechanisms between two metallic electrodes placed in a rarefied atmosphere, offers a valuable practical means of improving the performance of $\mathrm{HV}$ apparatus.

After describing the experimental apparatus, the results of the measurement carried out, the observations made by means of an electronic microscope and analysis by the EDS (energy dispersing spectrometer) of the electrode surfaces after breakdown, will be presented and commented upon.

\section{EXPERIMENTAL APPARATUS}

As shown diagrammatically in Figure 1, it is composed of three separate blocks.

A mechanical structure including a high-vacuum chamber and its pumping block, consisting of a primary pump, a turbomolecular pump and an ion pump.

The pressure measurements are taken with a Bayard and Alpert gauge. The interelectrode gap is adjusted with a micrometer having a resolution of $0.5 \mu \mathrm{m}$.

An electrical set including a HV supply of the Brandenburg type ( 0 to $30 \mathrm{kV}$ and 0 to $1.5 \mathrm{~mA}$ ), a voltage divider composed of a $1500 \mathrm{M} \Omega$ resistor in parallel with a capacitor $\mathrm{C}_{d}$ of $\sim 0.1 \mathrm{pF}$; and a $50 \Omega$ resistor $\mathrm{R}$, for recording the start of the current impulse.

The recording and processing of the electrical signals are carried out by a transient recorder, a computer and a digital memory oscilloscope of $100 \mathrm{MHz}$ sampling frequency.

By increasing the voltage from zero, the supply charges the capacitors $C_{d}, C_{1}$ and the parasitic capacitance $C_{0}$. At breakdown, the power

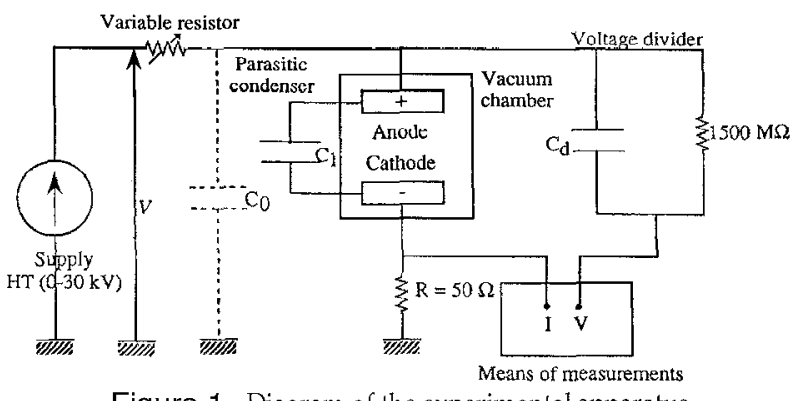

Figure 1. Diagram of the experimental apparatus.

necessary to produce the discharge is not totally provided by the HV supply, as the clectric current is limited to $1.5 \mathrm{~mA}$. It is the interelectrode capacitance $C_{1}$ as well as $C_{d}$ and $C_{0}$ which discharge themselves through the low impedance formed by the discharge between the two electrodes. The voltage drop at breakdown and the current impulse passing through the resistor $R$ are recorded by the equipment.

The pressure during measurements was $1.4 \times 10^{-4} \mathrm{~Pa}$. This has no effect on our measurements, because the medium free path of residual molecules is large enough compared with the electrode gap [1].

\section{EXPERIMENTAL RESULTS AND DISCUSSION}

\subsection{PREPARATION OF ELECTRODES}

The electrodes studied are made of silver $99.99 \%$ and alloys $\mathrm{AgNi}$ 80/20, $\mathrm{AgNi} 70 / 30$ and $\mathrm{AgNi} 60 / 40$. They are $2.9 \mathrm{~mm}$ thick, $8 \mathrm{~mm}$ in diameter, with a curvature radius of $16 \mathrm{~mm}$. Before being placed in the vacuum chamber, each contact is submitted to mechanical polishing, and then cleaned in an ethanol solution inside an ultrasonic tank. After being placed in the vacuum chamber, the contacts are submitted 
Table 1. The mean value $\left\langle V_{10}\right\rangle$ of 10 breakdown voltages.

\begin{tabular}{|c|c|c|}
\hline \hline Material & $\left\langle V_{10}\right\rangle$ & Std.Dev. \\
& $V$ & $V$ \\
\hline Ag 99.99 & 1420 & 130 \\
AgNi 80/20 & 2910 & 170 \\
AgNi 70/30 & 3390 & 180 \\
AgNi 60/40 & 3850 & 160 \\
\hline \hline
\end{tabular}

to conditioning treatment by successive breakdowns at $\mathrm{HV}$ in order to eliminate remaining surface contamination. This corresponds to an increase in the breakdown voltage until it reaches a stable value. This increase is due to the evaporation of adsorbed gas and deposits, the cleaning of the electrode surface, and the flattening of microprotrusions on the electrode surface. For a $1 \mu \mathrm{m}$ gap, and after a series of breakdowns, the mean value of ten breakdown voltages, and the standard deviations, are displayed in Table 1.

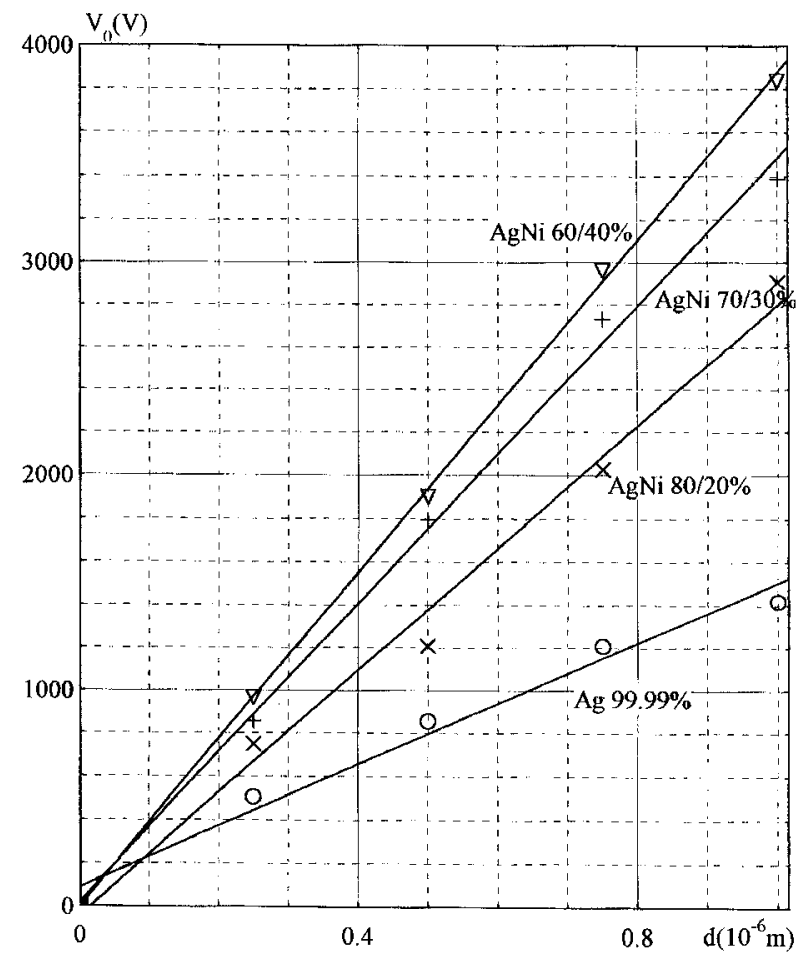

Figure 2. Breakdown voltage vs. electrode separation $(0<d<1 \mu \mathrm{m}$

\subsection{VARIATION OF BREAKDOWN VOLTAGE AND BREAKDOWN GRADIENT WITH ELECTRODE GAP}

In the work of Denholm et al. [2] on steel, copper and aluminum, as well as the work of Boyle et al. [3] on tungsten, a linear law between breakdown voltage $v_{0}$ and electrode gap $d$ has been inferred, $v_{0}=a d$ where $a$ is constant.

Our measurements regarding silver and silver-nickel alloys (Figure 2) have shown for $d<1 \mu \mathrm{m}$, that there exists a linear law $v_{0}=a d+b$, where $a$ and $b$ are constants. The values of $b$ are lower than the standard deviation of the breakdown voltage measurements. This shows that the
Table 2. The constants $a$ and $b$ which characterize each material.

\begin{tabular}{|c|c|r|}
\hline \hline Material & $\begin{array}{c}a \\
\mathrm{~V} / \mathrm{m}\end{array}$ & \multicolumn{1}{c|}{$\begin{array}{l}\mathrm{V} \\
\end{array}$} \\
\hline $\mathrm{Ag} 99.99$ & $14.2 \times 10^{8}$ & 90 \\
$\mathrm{AgNi} 80 / 20$ & $28.4 \times 10^{8}$ & -40 \\
$\mathrm{AgNi} 70 / 30$ & $34.6 \times 10^{8}$ & 24 \\
$\mathrm{AgNi} 60 / 40$ & $38.8 \times 10^{8}$ & 3 \\
\hline \hline
\end{tabular}

values of $b$ are in fact equal to zero and the linear law existing for silver and its nickel alloys is $v_{0}=a d$.

Constants $a$ and $b$ which characterize each type of material are given in Table 2.

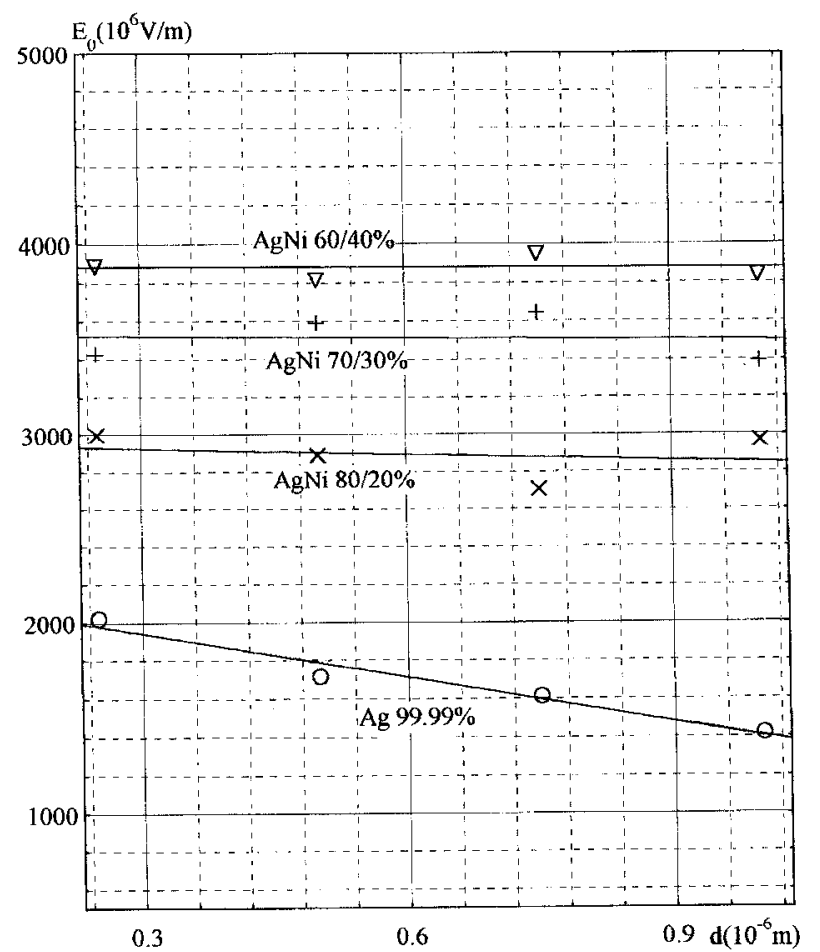

Figure 3. Breakdown gradient vs. electrode separation $(0<d<1 \mu \mathrm{m}$

The electric field at breakdown defined here by $E_{0}=v_{0} / d$ (where $v_{0}$ is the breakdown voltage and $d$ is the interelectrode gap) is independent of $d$ (Figure 3). This indicates that the process initiating discharge in vacuum is the electronic emission, which depends strongly on the electric field.

The breakdown plasma results from the interaction of the electronic flow with either electrode. Figure 3 also shows that the electric field at breakdown increases with the nickel content in the alloy. One of the interesting results of this study is the improvement of the insulation of the interelectrode space with the increase in nickel content in the silvernickel alloy.

For $1<d<30 \mu \mathrm{m}$, Figure 4 shows that the electric field at breakdown decreases with $d$. This total voltage effect has been observed by Tatarinova et al. [4]. In fact, the local electrostatic field $E_{l o c}$ at the tip of the microscopic cathode protrusion is highly amplified in comparison to the macroscopic field $E_{0}$. 


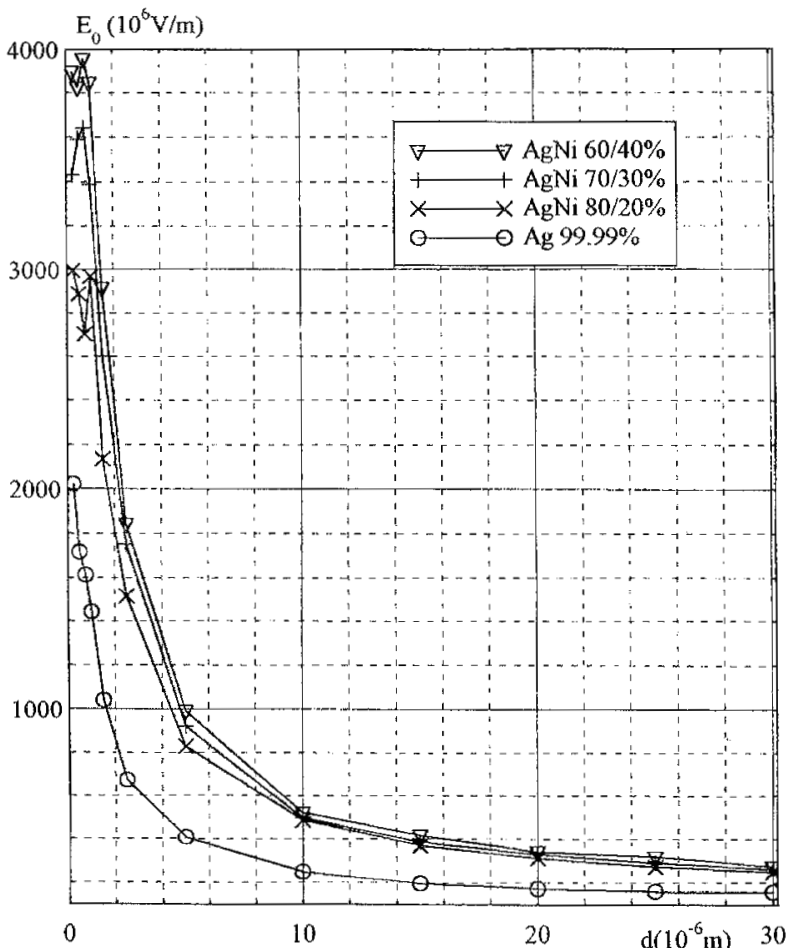

Figure 4. Breakdown gradient $v$ s. electrode separation $(0<d<$ $30 \mu \mathrm{m}$

$E_{l o c}=\beta E_{o}$, where $\beta$ is the field multiplication factor. When the interelectrode gap $d$ is low in comparison to microprotrusion height $H$, the values of $\beta$ are low. This requires a high macroscopic field to initiate breakdown. By increasing $d$ in comparison to $H$, the factor $\beta$ increases rapidly. This requires a lower macroscopic field to initiate breakdown than in the previous case.

Miller [5] has shown that at short gap lengths, the field multiplication. factor $\beta$ can be written as

$$
\beta=\frac{\beta_{\infty} d}{d+H}+\exp \left[-\frac{d}{H} \beta_{\infty}^{1 / 2}\right]
$$

where $\beta_{\infty}$ is the value of $\beta$ when the second electrode is located at a very large distance from the first one in comparison to $H$, and $d$ is the interelectrode gap. However, for values of $d$ close to that of $H$, the factor $\beta$ increases rapidly. Boyle et al. [3] have shown that the electrical breakdown of a gap between metal electrodes in high vacuum occurs when the current flowing between the electrodes exceeds by $65 \%$ the field emission current due to the applied field. They also have shown that at some small electrode separation, where the radius of curvature of the surface irregularities is much larger than the electrode separation, the field multiplication factor $\beta$ must be unity, and the increase in the apparent field at the shortest distance is a consequence of the decrease in the field multiplication factor of surface irregularities.

\subsection{EFFECT OF RESISTANCE PLACED IN SERIES WITH THE GAP}

A large resistance in series with the gap gives a low breakdown voltage (Figure 5). This is due to the fact that the breakdown with low stored

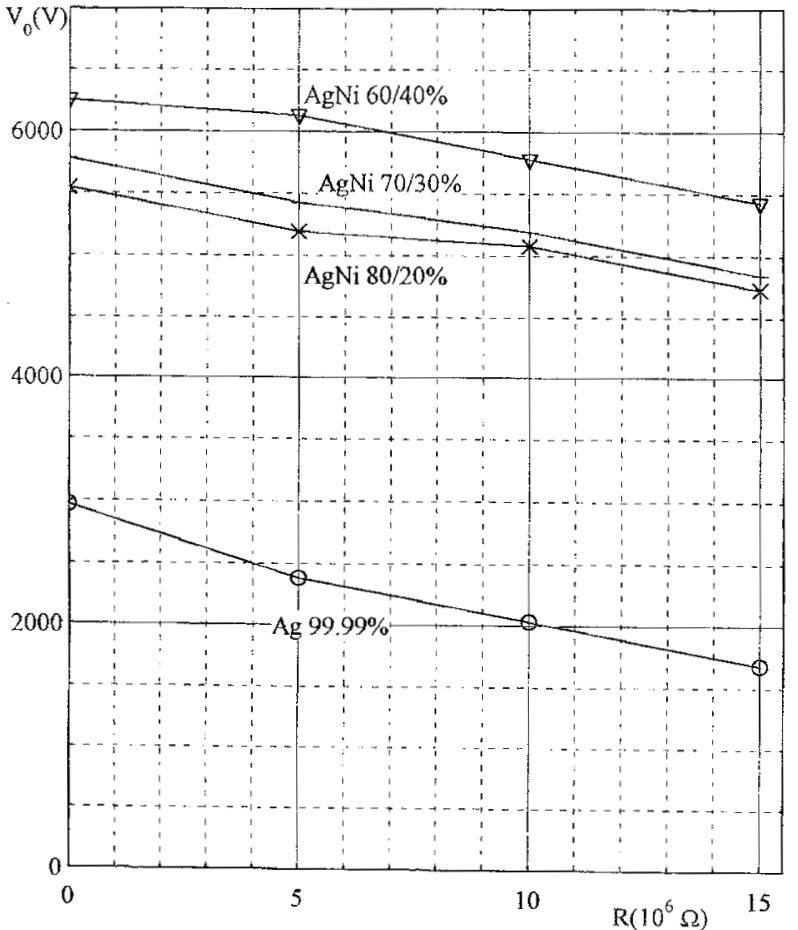

Figure 5. Influence of series resistance on breadown voltage $(d=$ $15 \mu \mathrm{m})$.

energy produces a finely divided metal spray, which roughens the cathode surface and gives a low breakdown voltage. The decrease in the energy dissipated reduces the area of the surface damaged by the arc.

Denholm [2] has shown that both the discharge of the gap capacitance and the breakdown mechanism itself produce a certain roughening on the cathode. He has also found that breakdown with a large resistance in series with the gap roughened the cathode. This caused high prebreakdown current to flow in the subsequent test. The more the cathode roughening, the lower the breakdown voltage.

\subsection{EFFECT OF HEATING OF ELECTRODES}

After several heating cycles of the electrodes at $600^{\circ} \mathrm{C}$, where the time of each cycle is represented in the abscissa of Figure 6 , we have observed that, in the case of silver electrodes, heating increases the breakdown voltage until it reaches a constant value. It is believed that degassing and smoothing of the microscopic irregularities of the electrode surface, reduces the field multiplication factor $\beta$, and hence increases the breakdown voltage.

An identical behavior has been found by Khalifa [6] and Slivkov [7]. It was shown that heating the electrodes improved the dielectric strength of the vacuum gap more than $4 \times$. This may be ascribed to the smoothing of the microscopic protuberances on the electrode surfaces, as well as to the partial desorption of their surface layers of occluded gases.

In the case of silver-nickel alloys, heating brings the breakdown voltage values of alloys close to that of silver. This is ascribed to the diffusion to the surface of silver atoms, which submerge the nickel atoms. 


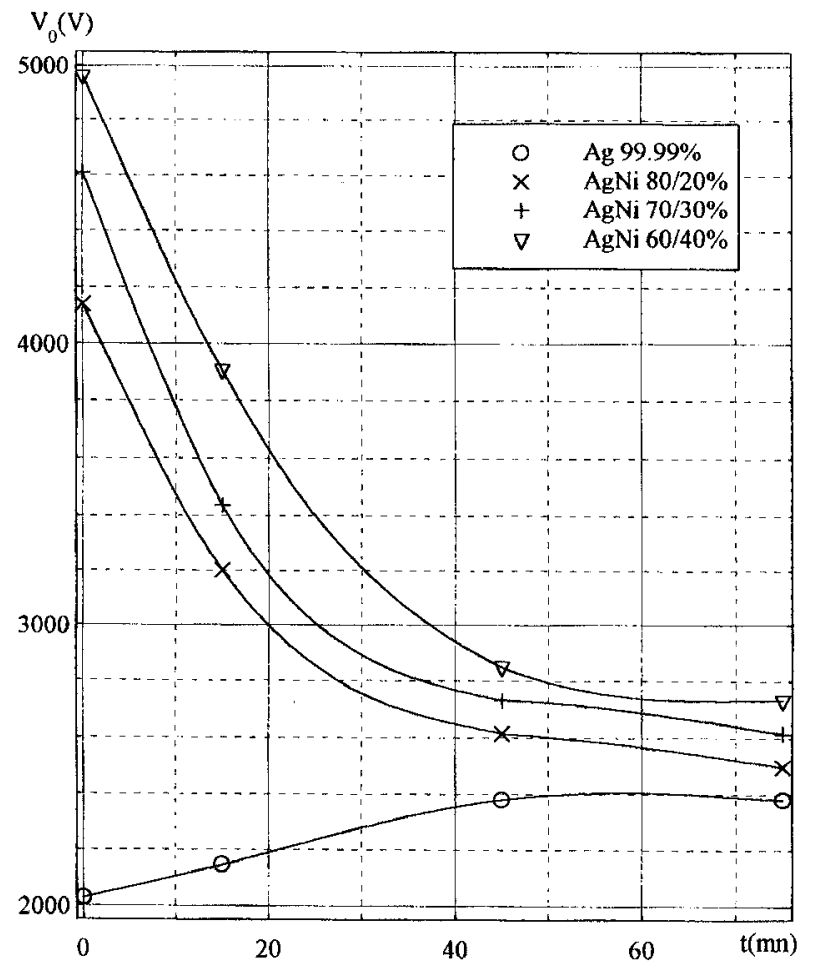

Figure 6. Effect of heating electrodes for varying times at $600^{\circ} \mathrm{C}(d=$ $5 \mu \mathrm{m})$.

This is due to the fact that the melting point of silver $\left(961.93^{\circ} \mathrm{C}\right)$ is lower than that of nickel $\left(1453^{\circ} \mathrm{C}\right)$. These observations reveal the multiple layer structure of these alloys.

In the works of Septier et al. [8] on Al-Li alloys, the authors have observed that lithium which has a lower melting point than aluminum diffuses to the surface by prolonged heating and lowers the work function.

\subsection{FALL TIME}

The fall time describes the metallic vapor propagation between electrodes. It is defined by the time period during which the voltage decreases from the $90 \%$ value down to the $10 \%$ value.

In the case of silver electrodes, we have observed that the voltage fall time depends linearly on the gap length, or on the decrease of breakdown field (Figure 7).

We think the neutralization of the space charge is caused mainly by anode vapor. The electric field slows the displacement of the ions in the vapor front. Therefore, the arc has an anodic origin. The field emission current from The small irregularities on the cathode evaporates anode material and the breakdown occurs in the resulting vapor when the power density at the anode reaches critical value.

In the case of AgNi alloys, the fall time is almost independent of the gap, and therefore independent of the electric field. This reveals that the breakdown results mainly from cathode processes. All positive ions in the vapor front have been pushed back to the cathode and the vapor front propagates in the direction of the anode with its initial velocity. This proves that the arc has a cathode origin. Breakdown is caused by a field emission current emanating from microscopic protrusions on the

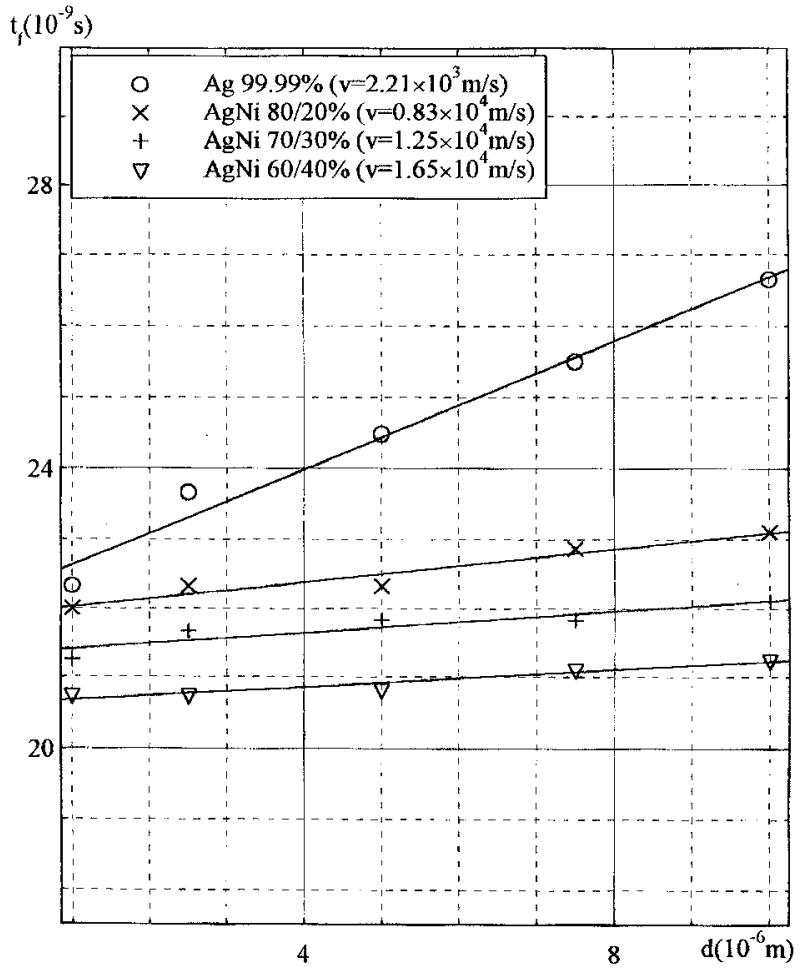

Figure 7. Fall time vs, electrode separation (the average velocity of metallic vapor propagation in the interelectrode space).

cathode surface, which explode and evaporate due to Joule heating. The fall time found in our measurements is in the order of $20 \mathrm{~ns}$.

From the linear representation slope of fall time vs. the gap, we deduced that the propagation velocity of metallic vapor is in the order of $10^{3} \mathrm{~m} / \mathrm{s}$ for silver and $10^{4} \mathrm{~m} / \mathrm{s}$ for alloys. This is in agreement with the works of Ravari [9] and Color [10].

Finally, the low values of the melting point, the latent heat, and the work function of $\mathrm{Ag}$ in comparison to those of AgNi alloy, have contributed to the anodic breakdown of silver electrodes, which is characterized by the evaporation and ionization of the anode material under the effect of the electronic bombardment.

\subsection{DELAY TIME}

The delay time is the time necessary to heat and evaporate enough anode material to cause breakdown. It is defined by the time period during which the voltage decreases without a detectable current increase. Figure 8 shows a limited delay time for alloys ( $<10 \mathrm{~ns}$ ) and a slightly higher one in the case of silver. Boyle et al. [3] have measured similar delay times. This confirms that we have anode type arcs in the case of $\mathrm{Ag}$ and cathode type arcs in the case of $\mathrm{AgNi}$.

\subsection{SEM AND EDS OF ELECTRODE SURFACES}

The observations of the electrode surfaces by means of an electronic microscope after one breakdown have shown the following.

In the case of a silver anode and a copper cathode, there are several circular pits on the anode surface, which sometimes join together to 


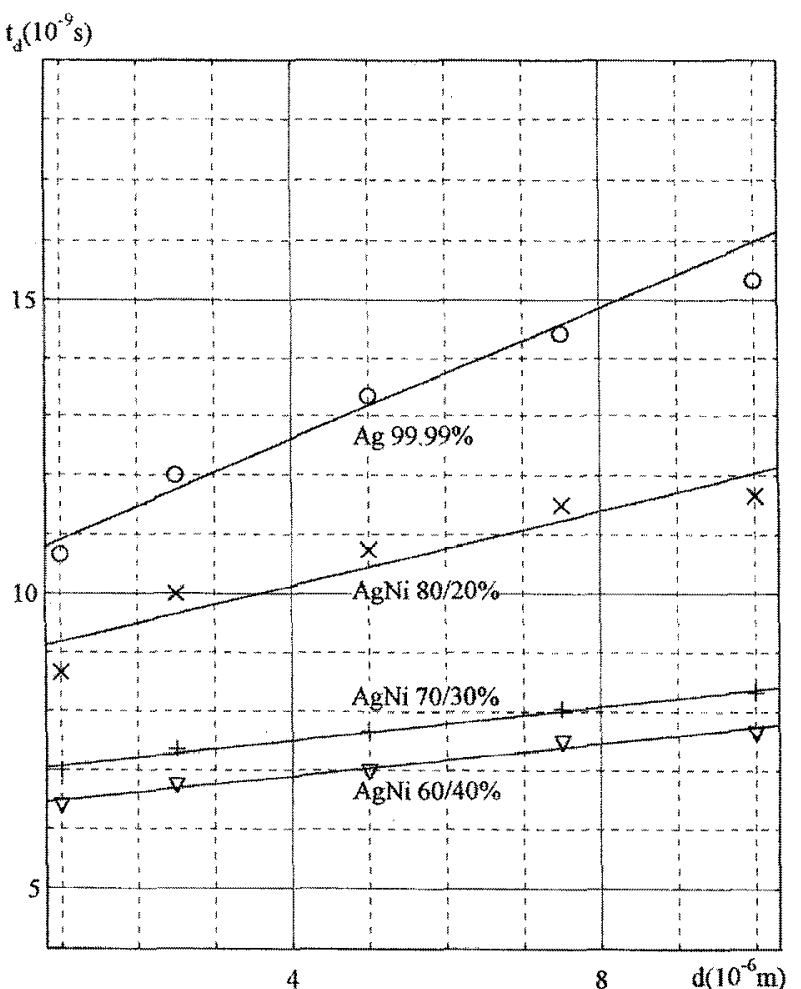

Figure 8. Delay time vs. electrode separation.

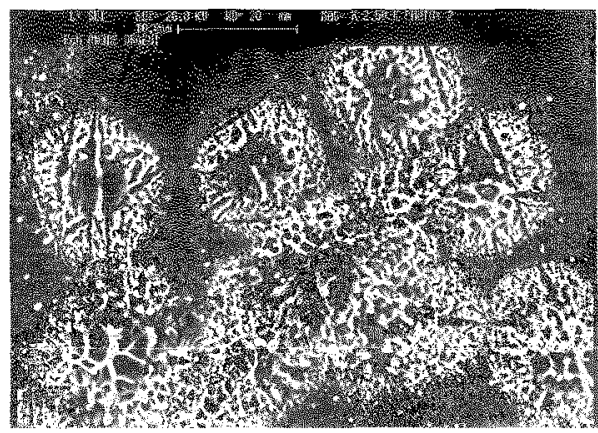

Figure 9. Photomicrograph $(\times 2500)$ of the $\mathrm{Ag} 99.99$ anode surface after one breakdown.

form one large spot (Figure 9). The observations, as well as the analysis of the electrode surface composition (two representative points) by EDS, have shown several fusion marks of the anode material on the anode (Figure 10) and some anode material marks on the cathode (Figures 11 and 12). This confirms that the breakdown is anodic and the most important transfer of material is from the anode to the cathode. This is in full agreement with Miller [11]. He has shown that the breakdown between two electrodes of relatively low melting points material causes fusion of the anode surface and the formation of anode spots.

In the case of a silver-nickel $60 / 40$ cathode and a copper anode, observations by means of an electronic microscope and analysis by EDS have shown that there exist several marks of localized fusion on the cathode surface (Figures 13 and 14), and a slight deposit of the cathode material on the anode surface (Figures 15 and 16). This proves that the breakdown has a cathodic origin and the transfer of material takes place mainly from the cathode to the anode. This is in full agreement with the
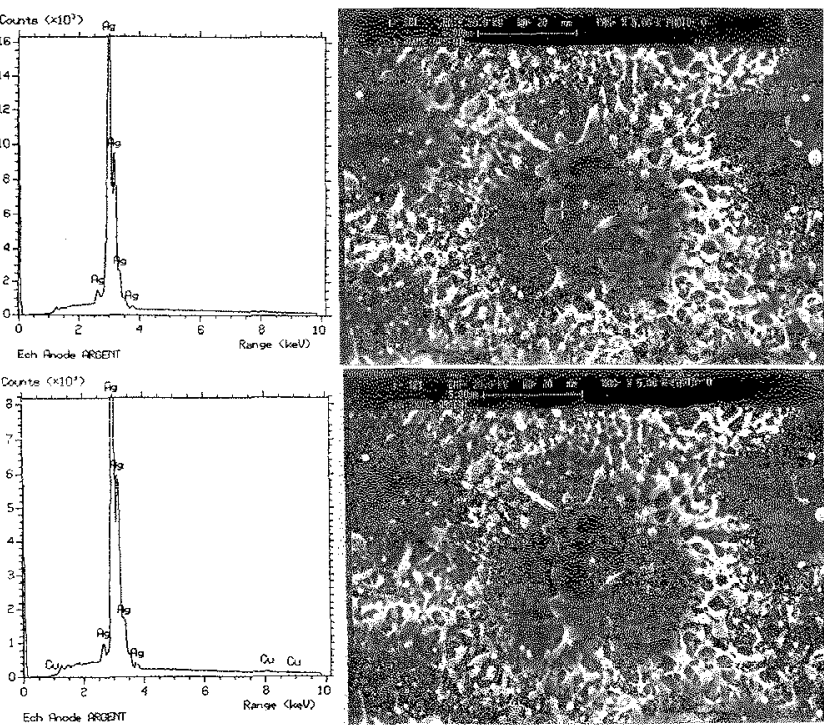

Figure 10. Analysis by EDS of two representative points (one bright and one dark) of the $\mathrm{Ag} 99.99$ anode surface after one breakdown.

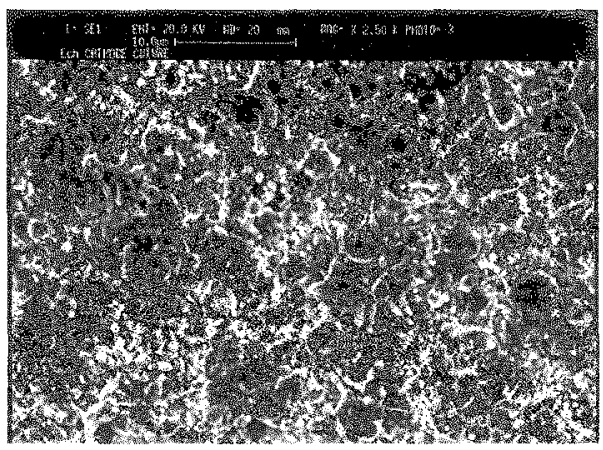

Figure 11. Photomicrograph $(\times 2500)$ of the $\mathrm{Cu} 99.99$ cathode surface after one breakdown.
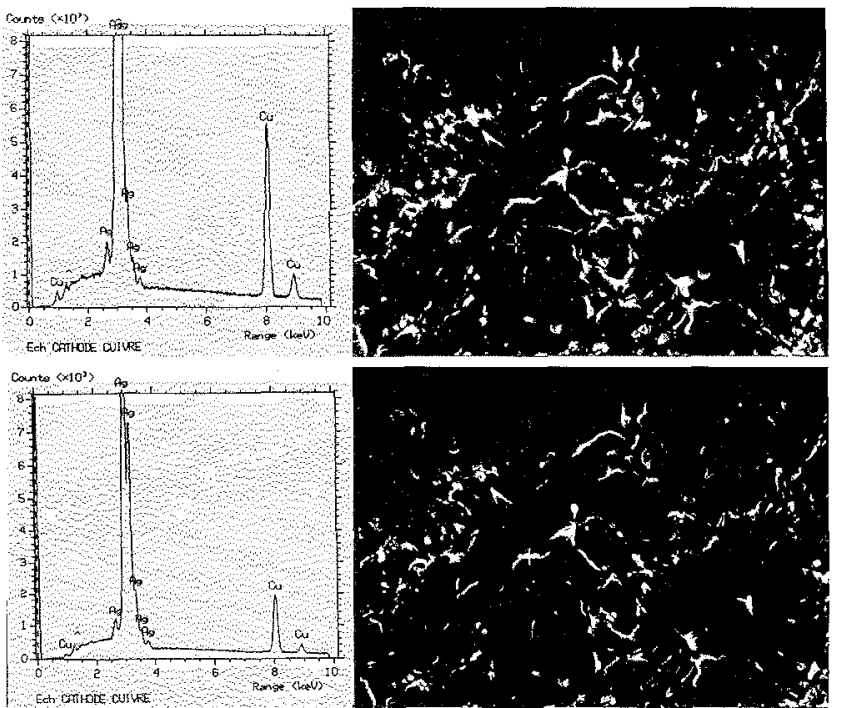

Figure 12. Analysis by EDS of two representative points (one bright and one dark) of the $\mathrm{Cu} 99.99$ anode surface after one breakdown.

works of Kimblin [12], who has shown that the cathode spots do not induce any important fusion on the cathode surface, because of their mobility and their limited power of dissipation. 


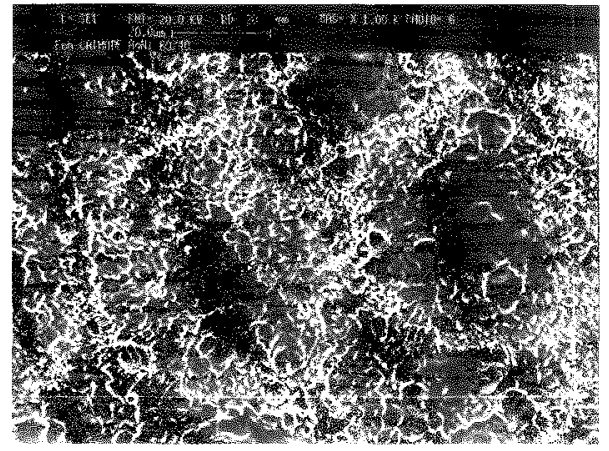

Figure 13. Photomicrograph $(\times 1000)$ of the $\mathrm{AgNi} 60 / 40$ cathode surface after one breakdown.
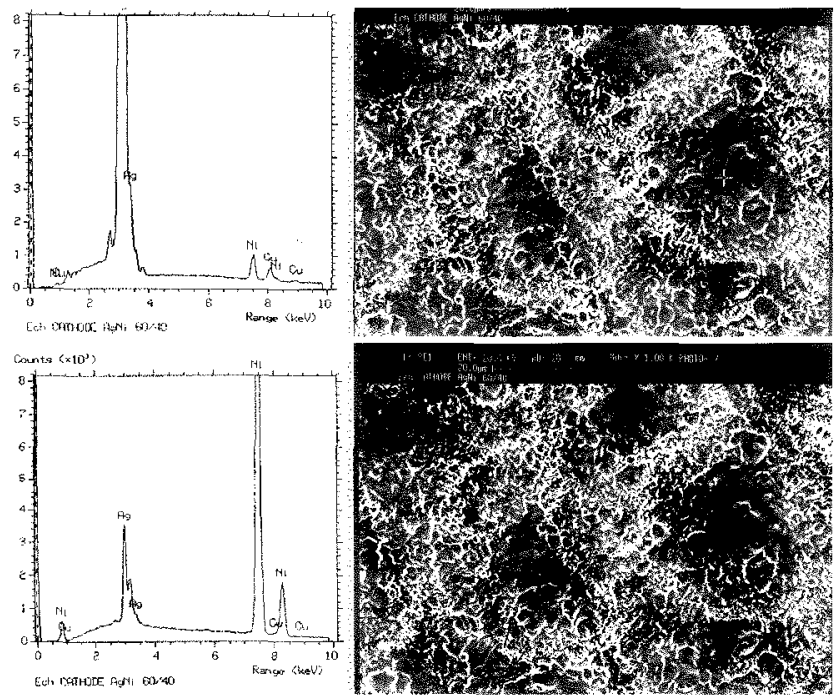

Figure 14. Analysis by EDS of two representative points (one bright and one dark) of the $\mathrm{AgNi} 60 / 40$ cathode surface after one breakdown.

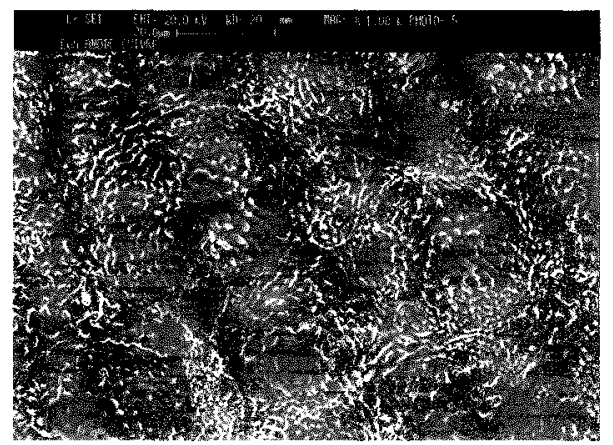

Figure 15. Photomicrograph $(\times 1000)$ of the Cu 99.99 anode surface after one breakdown.

\section{CONCLUSION}

$\mathrm{T}$ HE agreement between our experimental results and that of other authors, shows that our experimental apparatus is satisfactory in determining the electrical breakdown behavior in vacuum between two electrodes, in accordance with their composition.

We have found that, for silver and silver-nickel alloys, at the micrometer scale, the process initiating discharge in vacuum is electronic emission. The electric field values at the breakdown increase with the nickel content in the alloy. This helps to improve the insulation and achieves high resistance to erosion for low power arcs.
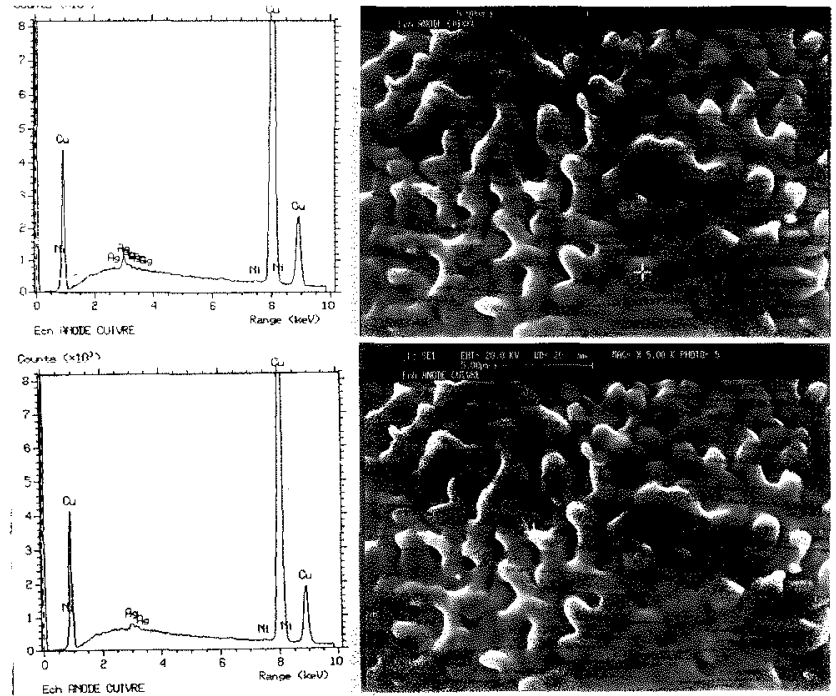

Figure 16. Analysis by EDS of two representative points (one bright and one dark) of the $\mathrm{Cu} 99.99$ anode surface after one breakdown.

A resistance placed in series with the gap reduces the breakdown voltage and limits the area of the electrode surfaces affected by this breakdown.

Heating silver electrodes cleans and smoothes the electrode surfaces. In the case of alloys, heating demonstrates their multiple layer structure. The observations through SEM, the analysis by EDS, and the measurements of the fall and delay times enabled us to show the origin of the electric arc for each of the materials studied.

\section{REFERENCES}

[1] E. S. Borovic and Batrakov, "Investigation of Breakdown in Vacuum", Soviet Physics-Technical Physics, Vol. 3, pp. 1811-1818, 1958.

[2] A. S. Denholm, "The Electrical Breakdown of Small Gaps in Vacuum", Canad. J. Phys., Vol. 36, pp. 476-493, 1958.

[3] W. S. Boyle, P. Kisliuk, and L. H. Germer, "Electrical Breakdown in High Vacuum", J. Appl. Phys., Vol. 6, pp. 720-725, 1955.

[4] N. V. Tatarinova and Yu. V. Grigoriev, "Total Voltage Effect and Electrode Porosity", XVI Int Symp on Discharge and Electrical Insulation in Vacuum. Moscow-Russia, Vol. 49, pp. 49-52, 1994.

[5] H. Craig Miller, "Change in Field Intensification Factor Beta of an Electrode Projection (Whisker) at Short Gap Lengths", J. Appl. Phys., Vol. 38, pp. 4501-4504, 1967.

[6] M. Khalifa, "Properties of Vacuum as a Switching Ambient", Canad. J. Tech., Vol. 34, pp. 304-315, 1956.

[7] I. N. Slivkov, "The Influence of The Electrode Temperature on the Electrical Breakdown Strength of a Vacuum Gap", Soviet Physics-Technical Physics, Vol. 2, pp. 707-709, 1958.

[8] A. Septier, F. Sabary, J. C. Dudek, and A. Boumiz, "An Alkali Dispenser Photocathode (Al-Li)-Ag-O-Li”, C. R. Acad. Sci. Paris, t. 314, serie. II, pp. 569-574, 1992.

[9] P. Ravari, Etude de la formation d'un arc dans le vide par l'analyse des temps de commutation, Thèse de 3ème cycle à l'Université de Paris sud, No d'ordre 107, 1971.

[10] M. Gollor, "Time Characteristics of the Vacuum Breakdown Under Impulse Stress", ETEP, Vol. 1, No 3, pp. 137-142, 1991.

[11] H. Craig Miller, "Vacuum Arc Anode Phenomena", IEEE Transactions on Plasma Science, Vol. 11, No 2, pp. 76-89, 1983. 
[12] C. W. Kimblin, "Vacuum Arc Ion Currents and Electrode Phenomena", Manuscript was received on 1 November 1996, in revised form 1 June 1997. Proc. IEEE, Vol. 59, pp. 546-555, 1971.

This paper is based on a presentation given at the 17 th International Symposium on Discharges and Electrical Insulation in Vacuum, July 1996, Berkeley CA, 1996. 